\title{
Psychoactive Medication Use in Intermediate-Care Facility Residents
}

\section{Citation}

Beers, Mark, Jerry Avorn, Stephen B. Soumerai, Daniel E. Everitt, David S. Sherman, and Susanne Salem. "Psychoactive medication use in intermediate-care facility residents." JAMA 260, no. 20 (1988): 3016-3020. doi:10.1001/jama.1988.03410200072028.

\section{Published Version}

doi:10.1001/jama.1988.03410200072028

\section{Permanent link}

http://nrs.harvard.edu/urn-3:HUL.InstRepos:32696183

\section{Terms of Use}

This article was downloaded from Harvard University's DASH repository, and is made available under the terms and conditions applicable to Other Posted Material, as set forth at http:// nrs.harvard.edu/urn-3:HUL.InstRepos:dash.current.terms-of-use\#LAA

\section{Share Your Story}

The Harvard community has made this article openly available.

Please share how this access benefits you. Submit a story.

\section{Accessibility}




\title{
Psychoactive Medication Use in Intermediate-Care Facility Residents
}

\author{
Mark Beers, MD; Jerry Avorn, MD; Stephen B. Soumerai, ScD; Daniel E. Everitt, MD; \\ David S. Sherman, RPh; Susanne Salem, MHSA
}

Despite the large number of elderly patients in nursing homes and the intensity of medication use there, few current data are available on patterns of medication use in this setting. We studied all medication use among 850 residents of 12 representative intermediate-care facilities in Massachusetts. Data on all prescriptions and patterns of actual use were recorded for all patients during one month. On average, residents were prescribed 8.1 medications during the month (interquartile range, 7.4 to 8.8 ) and actually received 4.7 (range, 4.2 to 5.4) medications during this period. More than half of all residents were receiving a psychoactive medication, with $26 \%$ receiving antipsychotic medication. Twenty-eight percent of patients were receiving sedative/hypnotics during the study month, primarily on a scheduled rather than an as-needed basis. Of patients receiving a sedative/hypnotic, $26 \%$ (range, $14 \%$ to $41 \%$ ) were taking diphenhydramine hydrochloride, a strongly anticholinergic hypnotic. Of those receiving one of the benzodiazepines, $30 \%$ were receiving long-acting drugs, generally not recommended for elderly patients. The typical benzodiazepine dose was equivalent to $7.3 \mathrm{mg}$ per patient per day of diazepam. The most commonly used antidepressant was amitriptyline hydrochloride, the most sedating and anticholinergic antidepressant in common use. These data indicate that despite growing evidence of the risks of psychoactive drug use in elderly patients, the nursing home population studied was exposed to high levels of sedative/hypnotic and antipsychotic drug use. Suboptimal choice of medication within a given class was common, and use of standing vs as-needed orders was often not in keeping with current concepts in geriatric psychopharmacology. Additional research is needed to assess the impact of such drug therapy on cognitive and physical functioning, as well as to determine how best to improve patterns of medication use in this vulnerable population.

(JAMA 1988;260:3016-3020)

From the Program for the Analysis of Clinical Strategies (Drs Beers, Avorn, Soumerai, Everitt, Mr Sherman, and Ms Salem), the Division on Aging (Drs Beers, Avorn, Soumerai, and Everitt and Mr Sherman), and the Department of Social Medicine and Health Policy (Drs Avorn and Soumerai). Harvard Medical School. Boston; the Gerontology Division, Department of Medicine, Beth israel Hospital, Boston (Drs Avorn and Everitt): and the Geriatric Research, Education and Clinical Center of BrocktonWest Roxbury Veterans Administration Medical Center, Boston (Dr Everitt). Dr Beers is now at the Center for Health Sciences, Department of Medicine, UCLA, Los Angeles

Rexrint requests to the Program for the Analysis of Clinical Strategies, Harvard Medical School, 643 Huntington Ave, Boston, MA 02115 (Dr Avorn). tutionalized elderly persons. This article describes a large-scale study of all medication use in 850 residents of 12 representative Massachusetts nursing homes. It represents one of the few detailed surveys of medication use performed in the last decade with a large cohort of long-term-care residents.

In 1976, the Office of Long-Term Care of the Department of Health, Education, and Welfare published one of the first comprehensive studies of medication use in such a population, based on a sample of 3458 nursing home patients covered by the Medicaid and Medicare programs. ${ }^{2}$ The report suggested serious problems of overuse and misuse of drugs in this population. Patients were found to be taking an average of 6.1 drugs, and nearly $50 \%$ of all residents were prescribed tranquilizers (a category that included antipsychotic medications and minor tranquilizers). Approximately $12 \%$ of all residents were prescribed two or more psychoactive drugs, with antipsychotic medications prescribed much more often than minor tranquilizers. About one third of all patients were prescribed sedative/hypnotics, and $9 \%$ were taking antidepressants. Of those receiving antidepressants, $38 \%$ were prescribed amitriptyline hydrochloride.

In a more recent study reviewing Medicaid patients residing in nursing homes in Tennessee, Ray et $a l^{3}$ found that $42 \%$ of those patients received antipsychotic medication. The authors concluded that their findings provided "epidemiologic evidence suggesting misuse of antipsychotic drugs in nursing homes." Further accounts of the overuse of psychoactive drugs in nursing homes were presented during widely 
reported congressional hearings in $19800^{4}$

Data collected regarding drug use in nursing home patients have relied on computerized databases that focused on Medicaid and Medicare patients. Although these sampling methods have the advantage of including large numbers of patients, they exclude half of long-term-care patients who pay for nursing home care through their own resources and, thus, may not be representative of the nursing home population in general. In addition, most studies have not collected data on actual use of as-needed (pro re nata [PRN]) orders, and so have not been able to measure the intensity of use of medication administered through this common nurse-mediated and very variable mechanism. Smaller studies have examined drug use in a single nursing home ${ }^{5-7}$ and may not be generalizable.

During the past decade, considerable evidence has accumulated and been published concerning the dangers of polypharmacy in elderly patients. ${ }^{1,8}$ Recommendations have included restrained use of medications, particularly those affecting the central nervous system, and the substitution of safer alternatives for many older drugs. Amitriptyline, the first available tricyclic antidepressant, is highly sedating and anticholinergic, two properties that often make it undesirable for elderly patients. Newer and safer antidepressants are now available and preferable. Diphenhydramine hydrochloride, an antihistamine with strong sedating properties, has been commonly used to induce sleep in the nursing home setting, but it too is strongly anticholinergic and, thus, is not a drug of choice for elderly patients. ${ }^{9}$ Flurazepam hydrochloride, diazepam, and chlordiazepoxide hydrochloride, the older benzodiazepines with very long half-lives in elderly patients, ${ }^{10-12}$ have been shown to present the risk of increased toxicity in aged patients; newer, shorter-acting benzodiazepines are generally preferable when benzodiazepines are needed. ${ }^{11}$

Increasing numbers of studies of toxic reactions to psychoactive drugs in elderly patients have demonstrated associated morbidity, including a high incidence of acute confusional states, ${ }^{13}$ hip fractures, ${ }^{14}$ and oversedation. The clinical literature on antipsychotic medications has failed to show specific benefit for most nonpsychotic elderly patients, ${ }^{16-17}$ although their toxicity has been well documented..$^{18}$ There is good evidence that these drugs have been seriously overused in nursing home patients. ${ }^{19}$

Although the knowledge base of geri- atric pharmacology has improved and such information has become more available, there have been remarkably few large-scale data published on patterns of medication use, and particularly on psychoactive drug use, in nursing homes in recent years; nor has there been any systematic evaluation of the impact of developments in geriatric research and teaching on actual practice in long-term-care facilities. This study was designed to explore this important but poorly documented aspect of the health care system.

\section{METHODS}

In developing a targeted educational intervention aimed at improving drug use in nursing homes, we studied baseline patterns of medication use among residents of 12 representative intermediate-care facilities (ICFs) in Massachusetts. A complete list of all ICFs in Massachusetts was obtained from the Massachusetts Department of Public Health. Because the eventual goal was to provide an educational intervention, homes with fewer than 40 ICF-level residents were excluded. We identified 339 homes in Massachusetts that met this criterion; those in eastern Massachusetts were considered for further study. To ensure that the homes represented typical geriatric facilities rather than those caring for deinstitutionalized mental hospital patients, homes were eliminated if they had greater than $20 \%$ of their residents admitted from inpatient psychiatric hospitals. Homes with active nurse practitioner prescribing were likewise excluded, as were facilities with preexisting relationships between the authors and consulting pharmacists or physicians in the homes. The remaining 26 homes were given information about the drug-use intervention. Ten homes declined to participate in a randomized trial, primarily because of changes in ownership or administration or labor disputes. Of the remaining 16 homes, 12 were enrolled in the study and four were retained as alternates on the basis of geographic distribution. A pilot survey of drug use over a twoweek period revealed no difference in average use of antipsychotic and sedative drugs between the study homes and the alternate homes.

\section{Data Collection and Analysis}

An interactive data collection program was written to guide research assistants in capturing medication-use data on a portable computer. In each facility, all medication data were recorded for all residents for an entire month. For all drugs prescribed, the program prompted for data regarding medication name (trade or generic), current regimen, dosage changes, start and stop orders, route of administration, and other changes in regimen during the month. A PRN use module made it possible to document the doses of PRN medications actually administered each day and sum them over the month. The software combined data on a given drug recorded as either its generic or trade name, as well as summing scheduled doses and PRN doses actually administered. Additional programming made it possible to convert regimens into equivalent milligrams of a prototype compound for each group (eg, chlorpromazine hydrochloride or diazepam), as well as analyze use by broad categories of drug (eg, all antipsychotic medication). In addition, the program also recorded the name of each patient's physician, the patient's age, sex, date of admission, payment source, current diagnoses, and the date and reason for hospitalizations that occurred during the study period.

Data were collected regarding all patients residing in the 12 study homes $(n=850)$. More than half $(n=441)$ of the study subjects were Medicaid patients. Because nursing homes rather than patients were sampled, analyses were performed with the nursing home as the unit of analysis. In addition, to control for the potential influence of outlier facilities and to make our results more generalizable to other ICFs, we measured drug utilization as the median and interquartile range of the measures of drug use. This method is more conservative when there are significant interhome differences in specific usage categories. To avoid considering drugs written for PRN use but not given, medications are described as having been "used" only if they were administered to the patient on at least five days in the study month.

\section{Nursing Homes Sampled}

To ensure that the homes studied were representative of ICFs throughout the state, we compared all available characteristics of each of the 339 Massachusetts ICFs that had 40 or more beds with those of the study homes, as indicated in Table 1. The study homes were found to be quite similar to the universe of homes regarding patterns of ownership and management; as noted in Table 1 , about $70 \%$ of Massachusetts homes with intermediate-care beds are owned and operated by for-profit corporations. Additional data for nonstudy homes were obtained from the Massachusetts Department of Public Health. Table 2 shows that the homes studied were comparable with all ICFs of similar size 
within $96 \mathrm{~km}$ (60 miles) of Boston with respect to the proportion of residents on Medicaid, under age 65 years, and over age 85 years.

\section{RESULTS}

\section{Demographics and Overall Drug Use}

The total sample consisted of $850 \mathrm{pa}-$ tients in 12 facilities; the median home had 70 patients, with an interquartile range of 60 to 80 patients. Unless otherwise stated, all results reported herein are the median of the 12 nursing home proportions or means; the interquartile ranges are indicated in parentheses.

As in most nursing home populations, the majority of residents, or $84 \%$ (range, $76 \%$ to $87 \%$ ), were female; their mean age was 85 years (range, 84 to 96 years). Sixteen percent of patients were male, with a mean age of 82 years (range, 76 to 84 years). Of all drug orders written, $48 \% \quad(n=7168$ orders; range, $37 \%$ to $52 \%$ ) were written for PRN use.

The average number of different medications ordered per patient during the month was 8.1 (range, 7.4 to 8.8 ). One fifth of all prescriptions were for over-the-counter analgesics and cathartics. Analysis of drugs actually given at least once each month and those given on at least five days each month demonstrated that patients received 5.5 (range, 4.7 to 6.0 ) or 4.7 (range, 4.2 to 5.4) different medications on average, respectively. Since these estimates included occasional short-term therapies (eg, antibiotics), the average number of concurrent drugs per day would be slightly lower. Only 35 patients (4\%) had no medication orders. There was no significant difference in overall drug use between men and women.

\section{Psychoactive Drug Use}

Nearly two thirds of the residents (65\%; range, $58 \%$ to $71 \%$ ) had orders written for one or more psychoactive medications, and 53\% (range, $48 \%$ to $59 \%$ ) actually used psychoactive drugs on five or more days during the study month (Table 3). These included sedative/hypnotics (including benzodiazepine tranquilizers), antipsychotics, and antidepressants. Barbiturates, antiseizure medications, antiparkinsonian drugs, lithium carbonate, and antihypertensives with known psychoactive properties were not included. Fortythree percent of orders (range, $35 \%$ to $48 \%$ ) written for psychoactive drugs were written for PRN use, but only $20 \%$ of those PRN orders were used. There was no difference between Medicaid and non-Medicaid patients in overall psychoactive drug use or in any subcategory of drug use.

Table 1.-Characteristics of Study Homes and All Massachusetts Nursing Homes With 40 or More Intermediate-Care Facility Beds

\begin{tabular}{lcc}
\multicolumn{1}{c}{ Characteristics } & $\begin{array}{c}\text { Study Homes } \\
(\mathbf{n = 1 2})\end{array}$ & $\begin{array}{c}\text { All Massachusetts } \\
\text { Homes }(\mathbf{N}=\mathbf{3 3 9})\end{array}$ \\
\hline Mean No. of intermediate-care facility beds & 75 & 66 \\
\hline Mean No. of total beds & 101 & 108 \\
\hline $\begin{array}{l}\text { Ownership, \% } \\
\text { Individual or partnership }\end{array}$ & 25 & 14 \\
\hline Nonprofit & 8 & 12 \\
\hline For-profit corporation & 67 & 72 \\
\hline
\end{tabular}

Table 2.-Patient Characteristics (Means) in Study Homes and All Massachusetts Nursing Homes With 60 or More Intermediate-Care Facility Beds*

\begin{tabular}{lcc}
\multicolumn{1}{c}{ Residents } & $\begin{array}{c}\text { Study Homes, \% } \\
(\mathbf{n}=12)\end{array}$ & $\begin{array}{c}\text { All Massachusetts } \\
\text { Homes, \% (n=109) }\end{array}$ \\
\hline On Medicaid & $62(\mathrm{SD}=26)$ & $73(\mathrm{SD}=23)$ \\
\hline From psychiatric institutions & 0 & $3(\mathrm{SD}=9)$ \\
\hline$<$ Age 65 y & $4(\mathrm{SD}=6)$ & $8(\mathrm{SD}=12)$ \\
\hline Age 85y & $49(\mathrm{SD}=10)$ & $43(\mathrm{SD}=14)$ \\
\hline
\end{tabular}

*Study homes are compared with all Massachusetts nursing homes with 60 or more intermediate-care facility beds within $96 \mathrm{~km}$ ( 60 miles) of Boston; based on data provided by the Massachusetts Department of Public Health.

Table 3. - Patterns of Prescription and Actual Use of Psychoactive Medications* in 12 Nursing Homes (850 Patients)

\begin{tabular}{ccc}
$\begin{array}{c}\text { No. of } \\
\text { Psychoactive Drugs }\end{array}$ & $\begin{array}{c}\text { Medications Ordered, } \\
\text { Median \% } \\
\text { (Interquartile Range) }\end{array}$ & $\begin{array}{c}\text { Medications Used,t } \\
\text { Median \% } \\
\text { (Interquartile Range) }\end{array}$ \\
\hline 0 & $34.9(29.1-41.5)$ & $47.1(40.9-52.4)$ \\
\hline 1 & $38.8(32.4-41.9)$ & $32.9(29.9-39.3)$ \\
\hline 2 & $20.6(19.0-26.3)$ & $15.2(12.8-20.1)$ \\
\hline$\geq 3$ & $6.6(1.3-8.7)$ & $2.6(0.0-4.3)$ \\
\hline
\end{tabular}

*includes antipsychotics, sedative/hypnotics, and antidepressants only,

tPatient received drug at least five days in study month.

Table 4.-Psychoactive Drug Use by Residents With Specific Diagnoses

\begin{tabular}{lccccc}
\multicolumn{1}{c}{ Diagnosis } & All Patients & $\begin{array}{c}\text { Recelving Any } \\
\text { Psychoactive } \\
\text { Medication }\end{array}$ & $\begin{array}{c}\text { Receiving } \\
\text { Antipsychotic } \\
\text { Medication }\end{array}$ & $\begin{array}{c}\text { Receiving } \\
\text { Antidepressant } \\
\text { Medication }\end{array}$ & $\begin{array}{c}\text { Receiving } \\
\begin{array}{c}\text { Sedative/Hypnotic } \\
\text { Medication }\end{array}\end{array}$ \\
\hline Organic brain syndrome & 150 & $94(63)$ & $58(39)$ & $8(5)$ & $57(38)$ \\
\hline Alzheimer's disease & 228 & $164(72)$ & $99(43)$ & $33(14)$ & $94(41)$ \\
\hline Schizophrenia/psychosis & 51 & $42(82)$ & $36(71)$ & $7(14)$ & $15(29)$ \\
\hline Depression & 116 & $96(83)$ & $46(40)$ & $47(40)$ & $56(48)$ \\
\hline
\end{tabular}

About one fifth of patients (21\%) had orders for two psychoactive medications during the study month; $7 \%$ of patients had orders for three or more psychoactive medications. Actual use was somewhat less (Table 3).

\section{Antipsychotic Drug Use}

One third of patients (270) had orders written for antipsychotic medications. During the study month, 26\% (range, $20.9 \%$ to $27.8 \%$ ) of all residents actually used a neuroleptic on five or more days. Most of these patients had a combination of scheduled neuroleptic prescriptions with additional PRN orders. Of all orders for antipsychotic medication written, $42 \%$ (range, $26.6 \%$ to $45.5 \%$ ) were for PRN use, and $58 \%$ for regular- ly scheduled regimens. However, only $11 \%$ (range, $0 \%$ to $17 \%$ ) of PRN orders were activated during the study month. Of those patients taking antipsychotics, the median of the average daily dose by home was $65 \mathrm{mg}$ per patient per day (range, 42 to $94 \mathrm{mg}$ per patient per day) in milligram equivalents of chlorpromazine $^{20,21} ;$ for individual patients, the highest dose observed was $2000 \mathrm{mg}$ per day. Only 36 patients receiving antipsychotic medications carried a diagnosis of schizophrenia or other psychosis; Alzheimer's disease, organic brain syndrome, and depression were each more common diagnoses in these patients (Table 4).

Haloperidol was the most commonly prescribed antipsychotic medication 
and was given to $43 \%$ (range, $26 \%$ to $52 \%$ ) of those receiving antipsychotics and to $10 \%$ of the total sample. Thioridazine hydrochloride was the second most commonly prescribed antipsychotic, given to $33 \%$ (range, $25 \%$ to $50 \%$ ) of those receiving antipsychotics and to $7 \%$ (range, $6 \%$ to $14 \%$ ) of the total population.

\section{Sedative/Hypnotic Drug Use}

Forty percent (range, $34 \%$ to $51 \%$ ) of patients were prescribed sedative/hypnotic drugs, and $28 \%$ (range, $23 \%$ to $41 \%$ ) actually used these drugs for at least five days during the study month. Of these, $82 \%$ were receiving such a - medication on a regularly scheduled basis. Most orders for minor tranquilizers and hypnotics were for regularly scheduled use; while many patients had both scheduled and PRN orders, just $13 \%$ of patients prescribed sedative/hypnotics had only PRN orders. Twenty-three percent (range, $19 \%$ to $31 \%$ ) of PRN orders for drugs in this class were used.

About one fourth (26\%; range, $14 \%$ to $41 \%$ ) of all patients receiving a sedative/hypnotic were prescribed diphenhydramine. Twenty percent (range, $11 \%$ to $25 \%$ ) of all patients and $63 \%$ (range, $48 \%$ to $74 \%$ ) of those receiving a sedative received a benzodiazepine. As with sedative/hypnotics in general, the majority of benzodiazepine orders were prescribed as a standing order (87\%; range, $64 \%$ to $100 \%$ ). Of those receiving benzodiazepines, 51 patients $(30 \%$; range, $15 \%$ to $39 \%$ ) were taking the long-acting drugs flurazepam, diazepam, or chlordiazepoxide; for $67 \%$ of these patients, the regimen was a standing order to be administered at least daily. The average consumption of benzodiazepines was $7.3 \mathrm{mg}$ per patient per day (range, 6.7 to $9.5 \mathrm{mg}$ per patient per day) in milligram equivalents of diazepam. ${ }^{20,21.22}$

\section{Antidepressant Drug Use}

Fourteen percent (range, 10\% to $17 \%$ ) of patients used antidepressants. These orders were written almost exclusively as regularly scheduled regimens, though two patients received the drug as a PRN bedtime hypnotic. There was no difference between men and women in overall use of antidepressants. While 47 (39\%) of the 119 patients receiving antidepressants had a diagnosis of depression recorded, the majority (61\%) did not (Table 4).

Of those receiving antidepressants, the largest group (26\%; range, $18 \%$ to $35 \%$ ) received amitriptyline. The other antidepressants used were desipramine hydrochloride, doxepin hydrochloride, trazodone hydrochloride, imipramine hydrochloride, nortriptyline hydrochloride, and maprotiline hydrochloride.

\section{COMMENT}

These data suggest that despite a growing literature on the risks of polypharmacy in elderly patients, total drug use has remained high in this sample of nursing homes. The Department of Health, Education, and Welfare Office of Long-Term Care study of 1976 found that nursing home residents had prescriptions for an average of 6.1 concurrent medications per patient on the day of the survey. On average, patients in our study homes were prescribed 8.1 different medications during a month. Of these orders, an average of 4.7 drugs were actually used on five or more days by these residents. Though drugrelated adverse effects are well publicized and the seriousness of such complications are well known, ${ }^{6,2-25}$ those chronically institutionalized elderly patients who are least able to cope with drug side effects appear to be at continued risk for experiencing them.

The nursing homes from which these findings come are reasonably representative of homes in Massachusetts and the Northeast in general. However, there are potential limits to the generalizability of these findings. We studied only intermediate-care patients. These are patients in need of less care than those admitted to skilled-nursing facilities, a selection criterion that would, if anything, tend toward lower medication use. Facilities with high proportions of deinstitutionalized psychiatric patients were not included in the study. On the other hand, the inclusion of all short-term drugs given during the study month (eg, antibiotics) somewhat increases the estimated number of drugs prescribed in comparison with the Department of Health, Education, and Welfare study, which was based on a single-day survey.

The use of PRN medications presents special problems in nursing homes. Such orders place the responsibility of deciding to implement drug therapy on the nursing staff. It has been previously shown that extensive use of PRN medication may adversely affect patient care $^{26.27}$ if monitoring is poor and if the nursing staff is not adequately trained in the use and side effects of such drugs. Some authors have also suggested an increased cost to the institution when PRN orders are overused. ${ }^{27}$ The data presented herein document a very high level of PRN ordering of psychoactive medications, of concern in a level of care (ICF) with fewer requirements for the presence of skilled nursing surveillance. Nearly half of all orders for psychoac- tive drugs were written for PRN use. In practice, nurses initiated use of only about one fifth of these PRN orders. Ironically, in those situations in which PRN use is generally preferred over regularly scheduled use (eg, as sedative/hypnotics), the data indicate that PRN use accounts for only a small fraction of drug administration.

In this study, over half of all patients were receiving psychoactive drugs; about one in four patients was taking two or more psychoactive medicines. Reliance on scheduled regimens of psychoactive medicines indicates that these drugs are not used transiently for periods of special need. Instead, this pattern of use is compatible with the concept of sedation as "chemical restraint."

In many cases, the best drug within a therapeutic class was underutilized. This is exemplified by the high use of diphenhydramine as a hypnotic, a drug with strong anticholinergic properties ${ }^{9}$ that can lead to confusion and worsening of dementia, constipation, and urinary retention. ${ }^{18,29}$ Likewise, nearly one third of those who received benzodiazepines were prescribed older, long-acting drugs that are known to accumulate in elderly patients ${ }^{12,30,31}$ and are associated with a high frequency of toxic reactions in this age group. ${ }^{32}$ These findings differ from that of James, ${ }^{33}$ who found a level of use of hypnotics much lower than this study did, and lower than that reported in the rest of the literature. He attributed this difference to more vigorous drug utilization review in the five facilities that agreed to participate in his survey.

Amitriptyline, the antidepressant with the highest anticholinergic and sedating properties, ${ }^{10,34}$ and least favored for geriatric patients, ${ }^{36}$ was given to about one fourth of those taking an antidepressant, despite the availability of medications less toxic for elderly patients, such as the secondary amines. (This percentage of use is comparable with that reported in 1976 , although the 1976 analysis of the Office of Long-Term Care considered perphenazine as an antidepressant, somewhat lowering the percentage of amitriptyline use.)

The usefulness of antipsychotic medications in nonpsychotic, elderly patients has been questioned, ${ }^{14-16}$ although these drugs represent a common approach to the very difficult problem of managing disruptive behavior in demented patients who may be a risk to themselves or others. The high frequency of toxic reactions to these drugs is well documented, with many older patients who take them experiencing orthostatic hypotension, Parkinson's syn- 
drome, tardive dyskinesia, akathisia, worsened confusion, dry mouth, constipation, oversedation, and urinary incontinence. ${ }^{18,32,36,37}$ Although the total use of these drugs in this study is slightly lower than that in earlier reports, previous studies included many chronically institutionalized psychotic patients, estimated to make up at least $8 \%$ of all nursing home residents ${ }^{38,89}$; these patients were in large part excluded from our sample.

These findings indicate that there is

\section{References}

1. Rowe JW, Besdine RW (eds): Health and Disease in Old Age. Boston, Little Brown \& Co Inc 1982, p 39 .

2. Physician's Drug Prescribing Patterns in Skilled Nursing Facilities, publication (OS)7650050. Office of Long-Term Care, US Dept of Health, Education, and Welfare, 1976.

3. Ray WA, Federspiel CF, Schaffner W: A study of antipsychotic drug use in nursing homes: Epidemiologic evidence suggesting misuse. Am J Public Health 1980;70:485-491.

4. Hearings Before the Select Committee on Aging, House of Representatives, 96th Cong, 2nd sess (1980).

5. Ingman S, Lawson I, Pierpaoli PG, et al: A survey of the prescribing and administration of drugs in a long-term care institution for the elderly. $J$ Am Geriatr Soc 1975;23:309-316.

6. Kalchthler T, Coccaro E, Lichtiger S: Incidence of polypharmacy in a long-term care facility. $J \mathrm{Am}$ Geriatr Soc 1977;25:308-313.

7. Bergman HD: Prescription of drugs in a nursing home. Drug Intell Clin Pharm 1975;9:365-368.

8. Avorn J, Lamy P, Vestal R: Prescribing for the elderly - safely. Patient Care 1982;16:14-62.

9. Regesteinn QR: Insomnia and sleep disturbances in the aged. $J$ Geriatr Psychiatry 1980; 13:153-171.

10. Lippman S: Drug therapy for depression in the elderly. Postgrad Med 1983;73:159-173.

11. Allen RM: Tranquilizers and sedative/hypnotics: Appropriate use in the elderly. Geriatrics 1986;41:75-88.

12. Meyer BR: Benzodiazepines in the elderly. Med Clin North Am 1982;66:1017-1034.

13. Smith L: Aging and drug response: Research priorities and future directions, in Jarvik $L$ Greenblatt DJ, Harman D, et al (eds): Clinical need for considerably more effort to improve the use of psychoactive drugs in institutionalized elderly patients. Psychoactive medications continue to be used with high frequency and selection of drug is often suboptimal. Further analysis is required of the factors that influence drug use in nursing homes. Many of these may represent problems of inadequate staffing as well as information deficits among prescribers. There is a pressing need to study the clinical impact of such high levels of psy-

Pharmacology and the Aged Patient. New York Raven Press, 1981, pp 207-215.

14. Ray WA, Grifín MR, Schaffner W, et al: Psy chotropic drug use and the risk of hip fracture. $N$ Engl J Med 1987;316:363-369.

15. Helms P: Efficacy of antipsychotics in the treatment of the behavioral complications of dementia: A review of the literature. $J$ Am Geriatr Soc 1985;33:206-209.

16. Barnes R: Efficacy of antipsychotic medication in behaviorally disturbed dementia patients. $A m J$ Psychiatry 1982;139:1170-1174.

17. Raskin D: Antipsychotic medications and the elderly. J Clin Psychiatry 1985;46:136-140.

18. Jenike $M$ : Psychosis, rage and violence, in Handbook of Geriatric Psychopharmacology. Littleton, Mass, PSG Publishing Co Ine, 1985, pp 22 29.

19. Butler R: The overuse of tranquilizers in older patients. Int J Aging Hum Dev 1976;7:185-187. 20. AMA Dmug Evaluations, ed 5. Chicago, American Medical Association, 1986, p 112.

21. Goodman A, Gilman L, Gilman A (eds): The Pharmacological Basis of Therapeutics. New York, MacMillan Publishing Co Inc, 1980, p 350.

22. Everitt DE, Avorn J: Drug prescribing for the elderly. Arch Intern Med 1986;146:2393-2396.

23. Lang $L$, Kabat $H$ : Drug interactions in nursing home patient prescriptions. JAMA 1970;10:674677.

24. Cooper J, Wellins I, Fish KH Jr, et al: A sevennursing home study: Frequency of potential drug. drug interactions. J Am Pharm Assn 1975;15:2427,31 .

25. Lavanturier MD, Talley RB, Hefner DL, et al: Drug utilization and potential drug-drug interactions. J Am Pharm Assn 1976;16:77-81.

26. Howard J, Strong K Sr, Strong KE Jr: Medica- choactive drug use in this population to determine whether more judicious use of medications would result in reduced levels of disability in these already impaired elderly patients.

This work was funded by a grant from the John A. Hartford Foundation.

The authors are grateful to Susanne Bellavance for administrative assistance in the coordination of this research, Christina Casteris, MS, for analysis of the data, Sharon Hawley for data collection, Gail Gregg for consultation on software development, and Steven Rappaport, MD, for his assistance in the early phase of this project.

tion procedures in a nursing home: Abuse of $\mathrm{PRN}$ orders. J Am Geriatr Soc 1977;25:83-84. 27. Brown C, Kirk K: PRN drug utilization in Indiana long-term care facilities. Hosp Pharm 1984;19:692-696.

28. Covert $A$ : The use of mechanical and chemical restraints in nursing homes. $J$ Am Geriatr Soc 1977;25:85-89.

29. Resnick N: Urinary incontinence in the elderly Medical Grand Rounds 1984;3:281-290.

30. Lader M, Petursson H: Rational use of anxiolytic/sedative drugs. Dmigs 1983;25:514-528.

31. Greenblatt D, Sellers E, Shader R: Drug therapy: Drug disposition in old age. $N$ Engl $J \mathrm{Med}$ 1982;306:1081-1088.

32. Salzman C: Key concepts in geriatric psychopharmacology: Altered pharmacokinetics and polypharmacy. Psychiatr Clin North Am 1982;5:181190.

33. James DS: Survey of hypnotic drug use in nurs ing homes. J Am Geriatr Soc 1985;33:436-439.

34. Glassman A, Carino J: Adverse effects of tricyclic anti-depressants: Focus on the elderly. Adv Biochem Psychopharmacol 1984;39:391-398.

35. Georgotos A, Cooper T: The treatment of affec tive disorders in the elderly. Psychopharmacol Bull 1983; 19:226-237.

36. Baldessarini R: Antipsychotic agents, in Che motherapy in Psychiatry. Cambridge, Mass, Harvard University Press, 1977, p 44.

37. Vestal R: Drug use in the elderly: A review of the problems and special considerations. Drugs 1978;16:358-382

38. Rovner B, Rabins P: Mental illness among nursing home patients. Hosp Community Psychiatry 1985;36:119-120.

39. Carling PJ: Nursing homes and chronic mental patients. Schizophr Bull 1981;7:574-579. 